\title{
Arcanolysin is a cholesterol-dependent cytolysin of the human pathogen Arcanobacterium haemolyticum
}

\author{
B Helen Jost', Erynn A Lucas', Stephen J Billington², Adam J Ratner ${ }^{3^{*}}$ and David J McGee ${ }^{4^{*}}$
}

\begin{abstract}
Background: Arcanobacterium haemolyticum is an emerging human pathogen that causes pharyngitis, wound infections, and a variety of occasional invasive diseases. Since its initial discovery in 1946, this Gram positive organism has been known to have hemolytic activity, yet no hemolysin has been previously reported. A. haemolyticum also displays variable hemolytic activity on laboratory blood agar that is dependent upon which species the blood is derived.

Results: Here we describe a cholesterol-dependent cytolysin (CDC) secreted by A. haemolyticum, designated arcanolysin (aln), which is present in all strains $(n=52)$ tested by DNA dot hybridization. Among the known CDCs, ALN is most closely related to pyolysin (PLO) from Trueperella (formerly Arcanobacterium) pyogenes. The aln probe, however, did not hybridize to DNA from T. pyogenes. The aln open reading frame has a lower mol \%G+C (46.7\%) than the rest of the A. haemolyticum genome (53.1\%) and is flanked by two tRNA genes, consistent with probable acquisition by horizontal transfer. The ALN protein $(\sim 64 \mathrm{kDa})$ contains a predicted signal sequence, a putative PEST sequence, and a variant undecapeptide within domain 4 , which is typically important for function of the toxins. The gene encoding ALN was cloned and expressed in Escherichia coli as a functional recombinant toxin. Recombinant ALN had hemolytic activity on erythrocytes and cytolytic activity on cultured cells from human, rabbit, pig and horse origins but was poorly active on ovine, bovine, murine, and canine cells. ALN was less sensitive to inhibition by free cholesterol than perfringolysin $\mathrm{O}$, consistent with the presence of the variant undecapeptide.
\end{abstract}

Conclusions: ALN is a newly identified CDC with hemolytic activity and unique properties in the CDC family and may be a virulence determinant for A. haemolyticum.

\section{Background}

Arcanobacterium haemolyticum, a Gram positive, pleomorphic rod, causes wound infections and pharyngitis and can occasionally cause more severe invasive diseases such as endocarditis, meningitis, septic arthritis, pneumonia and osteomyelitis in humans [1]. There is strong epidemiologic evidence for $A$. haemolyticum being the only or primary isolate from throat specimens of some humans with pharyngitis [1-4] and these data suggest that the number of cases per year of $A$. haemolyticum-

\footnotetext{
* Correspondence: ar127@columbia.edu; dmcgee@|suhsc.edu

${ }^{3}$ Columbia University, Department of Pediatrics and Microbiology \& Immunology, 650 W 168 ${ }^{\text {th }}$ Street BB443, New York, NY 10032, USA

${ }^{4}$ Louisiana State University Health Sciences Center-Shreveport, Department of Microbiology \& Immunology, 1501 Kings Highway, Shreveport, LA 71130, USA

Full list of author information is available at the end of the article
}

mediated pharyngitis is $\sim 240,000-480,000$ with $0.5-1$ million lost work days in the United States. The organism, previously in the Corynebacterium genus, was classified as the first member of the genus Arcanobacterium [5]. The other members of the genus are uncommonly isolated and remain largely uncharacterized, with the exception of Trueperella (Arcanobacterium) pyogenes, which is an important opportunistic livestock pathogen [6].

Little is known about $A$. haemolyticum virulence factors with the exception of a phospholipase D (PLD) [7], which causes dermonecrosis [8]. We recently described the ability of PLD to reorganize host membrane lipid rafts, leading to enhanced bacterial adhesion [9]. Furthermore, A. haemolyticum was able to invade HeLa cells and once intracellular, PLD was able to kill host
C Biomed Central

(c) 2011 Jost et al; licensee BioMed Central Ltd. This is an Open Access article distributed under the terms of the Creative Commons Attribution License (http://creativecommons.org/licenses/by/2.0), which permits unrestricted use, distribution, and reproduction in any medium, provided the original work is properly cited. 
cells via direct necrosis [9]. These effects could potentially lead to bacterial dissemination to deeper tissues.

It is thought that clinical microbiology laboratories often miss $A$. haemolyticum in clinical specimens due to the organism's weak hemolytic activity on the commonly-used sheep blood agar, and therefore it may be misinterpreted as commensal diphtheroids and the isolate discarded. However, this organism displays more pronounced hemolysis on human and rabbit blood $[10,11]$. The organism has been known to have hemolytic activity since its initial discovery in 1946 [12], yet no bona fide hemolysin has been previously reported. PLD itself is not directly hemolytic, but causes synergistic hemolysis with bacteria that express cholesterol oxidase [13], prompting a search for the A. haemolyticum hemolysin. Possible clues to the identity of the A. haemolyticum hemolysin come from studies on the hemolytic bacterium $T$. pyogenes, which is closely related to $A$. haemolyticum. T. pyogenes expresses PLO, a member of the cholesterol-dependent cytolysin (CDC) toxin family, as its primary virulence factor and this molecule is a hemolysin [14]. Thus, we hypothesized that the hemolytic activity expressed by $A$. haemolyticum was due to the presence of an uncharacterized CDC.

Here we report the identification and characterization of a CDC from A. haemolyticum, designated arcanolysin (ALN). We show that ALN has several distinct structural features among the CDC family and demonstrate that ALN is cholesterol-dependent and provide evidence that ALN has variable hemolytic and cytotoxic activity against mammalian cells from different species. We propose ALN is the long, sought-after hemolysin.

\section{Methods}

\section{Bacteria and growth conditions}

ATCC 9345 is the A haemolyticum type strain. The other A. haemolyticum strains used in this study were archival isolates obtained from diverse human clinical cases (Table 1). A. haemolyticum and Escherichia coli strains were grown as previously described [9].

\section{DNA techniques}

E. coli DH5 $\alpha \mathrm{MCR}$ plasmid DNA extraction, transformation, DNA restriction, ligation and agarose gel electrophoresis were by standard methods [15]. DNA hybridization was performed using the DIG DNA Labeling and Detection Kit (Roche). PCR DNA amplification was performed using Vent DNA polymerase (NEB) for 35 cycles of $1 \mathrm{~min}$ at $94^{\circ} \mathrm{C}, 1 \mathrm{~min}$ at $50^{\circ} \mathrm{C}$ and $1 \mathrm{~min} / \mathrm{kb}$ at $72^{\circ} \mathrm{C}$, with a final extension step of $72^{\circ} \mathrm{C}$ for $7 \mathrm{~min}$.

\section{Nucleotide sequence determination and analysis}

Prior to the recent GenBank deposit of the $1.986 \mathrm{MB}$ genome from strain ATCC9345 (= DSM20595 = 11018)
[16], we sequenced the same strain to $>20 \times$ coverage (454 Life Sciences), with $\sim 1.945 \mathrm{MB}$ of unique sequence (> 98\% complete) with essentially identical sequence data. A translated ORF with amino acid similarity to CDCs, Arch_1062, was identified within this sequence. Oligonucleotide primers flanking this ORF were used to amplify the region by PCR. The nucleotide sequence was confirmed by automated DNA sequencing of both strands. The aln sequence data and flanking regions were submitted to the GenBank/EMBL/DDBJ databases under accession number FJ785427.

Database searches were performed using the BlastX and BlastP algorithms [17]. tRNA sequences were identified using the tRNAscan-SE program [18]. Signal sequence prediction was performed using SignalP [19]. Transcriptional terminators were identified using mfold [20]. Multiple sequence alignments were performed using CLUSTAL W [21], and tree construction was with the neighbor-joining algorithm and midpoint rooting, carried out in MacVector version 12.0.3 (MacVector, Inc.). PEST sequence prediction used the pestfind algorithm http://emboss.bioinformatics.nl/cgi-bin/emboss/ epestfind.

\section{Cloning and purification of a recombinant, $6 x \mathrm{His}$ tagged- ALN (His-ALN)}

The aln gene, without the signal sequence, was amplified from A. haemolyticum ATCC9345 genomic DNA by PCR with His-ALNF (5'-CCCGGCGTTGCGGATCCAGTTGACGC-3') and ALN5 (5'-GGACCTTCTCGAGTATGTATCACTC-3') encoding BamHI and XhoI sites (underlined in the primer sequence), respectively. These primers amplified a 1,669 bp product. The PCR fragment was digested with BamHI-XhoI and cloned into pTrcHisB (Invitrogen), to generate pBJ51, which encoded the $63.7 \mathrm{kDa}$ His-ALN. The final His-ALN translational fusion protein thus has the MWVGSQKHYFFYQDRGKIMTRRFLATVAGTALLAGAFAPGVAFG signal sequence removed and replaced with the sequence from the vector that leads to MGGSHHHHHHGMASMTGGQQMGR-

DLYDDDDKDP (6 His underlined). No other ALN native amino acids were removed. Cultures for purification of His-ALN were grown and lysed as described [9]. His-ALN was purified from the soluble cell fraction using TALON Metal Affinity Resin, as described (Clontech). His-ALN was eluted from the resin with $50 \mathrm{mM}$ imidazole, $20 \mathrm{mM}$ Tris- $\mathrm{HCl}, 100 \mathrm{mM} \mathrm{NaCl}$, pH 8.0 (elution buffer). Total protein concentration was determined using Bradford Protein Assay Reagent (Bio-Rad).

For some experiments ALN was amplified from ATCC 9345 DNA using the primers ALN26-F (GCCGCCGCTAGCGTTGACGCTTCAACACAAACCGATCC) and ALN-R (GCCGCCCTCGAGTCACTCG 
Table 1 Arcanobacterium strains used in this study.

\begin{tabular}{|c|c|c|}
\hline $\begin{array}{l}\text { Strain } \\
\text { (all } A \text {. haemolyticum except as noted) }\end{array}$ & Relevant characteristics & Source \\
\hline AhS1 & Biotype S*; wound infection; 73 year old male; 1991 & Petteri Carlson \\
\hline AhS2 & Biotype S; paronychia; 16 year old male; 1991 & Petteri Carlson \\
\hline AhS3 & Biotype S; wound infection; 11 year old male; 1991 & Petteri Carlson \\
\hline AhS4 & Biotype S; infected leg ulcer; 47 year old male; 1991 & Petteri Carlson \\
\hline AhS5 & Biotype S; wound infection; 64 year old male; 1991 & Petteri Carlson \\
\hline AhS6 & Biotype S; wound infection; 43 year old male; 1991 & Petteri Carlson \\
\hline AhS7 & Biotype S; infected leg ulcer; 68 year old female; 1991 & Petteri Carlson \\
\hline AhS8 & Biotype S; wound infection; 62 year old male; 1991 & Petteri Carlson \\
\hline AhS9 & Biotype S; wound infection; 38 year old male; 1991 & Petteri Carlson \\
\hline AhS10 & Biotype S; paronychia; 21 year old male; 1991 & Petteri Carlson \\
\hline AhS11 & Biotype S; pharyngitis; 3 year old male; 1991 & Petteri Carlson \\
\hline AhS12 & Biotype S; pharyngitis; 23 year old female; 1992 & Petteri Carlson \\
\hline AhS13 & Biotype S; pharyngitis; 28 year old female; 1992 & Petteri Carlson \\
\hline AhS14 & Biotype S; pharyngitis; 23 year old female; 1992 & Petteri Carlson \\
\hline AhS15 & Biotype S; pharyngitis; 20 year old male; 1992 & Petteri Carlson \\
\hline AhS16 & Biotype S; sinusitis; 41 year old male; 1990 & Petteri Carlson \\
\hline AhS17 & Biotype S; sinusitis; 65 year old female; 1991 & Petteri Carlson \\
\hline AhS18 & Biotype S; pharyngitis; 12 year old male; 1992 & Petteri Carlson \\
\hline AhS19 & Biotype S; pharyngitis; 20 year old female; 1992 & Petteri Carlson \\
\hline AhS20 & Biotype S; pharyngitis; 34 year old male; 1992 & Petteri Carlson \\
\hline AhS21 & Biotype S; peritonsillar abscess; 15 year old male; 1996 & Petteri Carlson \\
\hline AhS22 & Biotype S; pharyngitis, pneumonia; 42 year old male; 1996 & Petteri Carlson \\
\hline AhS23 & Biotype S; diabetic foot gangrene; 45 year old male; 1997 & Petteri Carlson \\
\hline AhS24 & Biotype S; tonsillitis; 16 year old female; 1998 & Petteri Carlson \\
\hline AhS25 & Biotype S; metatarsal osteitis; 37 year old male; 1998 & Petteri Carlson \\
\hline AhR26 & Biotype R; wound infection; 43 year old male; 1991 & Petteri Carlson \\
\hline AhR27 & Biotype R; wound infection; 53 year old male; 1991 & Petteri Carlson \\
\hline AhR28 & Biotype R; pharyngitis; 13 year old female; 1991 & Petteri Carlson \\
\hline AhR29 & $\begin{array}{l}\text { Biotype R (uncertain); peritonsillar abscess; } 18 \text { year old male; } \\
1991\end{array}$ & Petteri Carlson \\
\hline AhR30 & Biotype R; sinusitis; 14 year old male; 1992 & Petteri Carlson \\
\hline AhR31 & Biotype R; peritonsillar abscess; 21 year old male; 1986 & Petteri Carlson \\
\hline AhR32 & Biotype R; peritonsillar abscess; 15 year old female; 1992 & Petteri Carlson \\
\hline AhR33 & Biotype R; pharyngitis; 26 year old male; 1992 & Petteri Carlson \\
\hline AhR34 & Biotype R; pharyngitis; 15 year old male; 1992 & Petteri Carlson \\
\hline AhR35 & Biotype R; pharyngitis; 18 year old male; 1992 & Petteri Carlson \\
\hline AhR36 & Biotype R; pharyngitis; 21 year old male; 1992 & Petteri Carlson \\
\hline AhR37 & Biotype R; peritonsillar abscess; 15 year old female; 1992 & Petteri Carlson \\
\hline AhR38 & Biotype R; wound infection; 21 year old female; 1992 & Petteri Carlson \\
\hline AhR39 & Biotype R; pharyngitis; 18 year old female; 1992 & Petteri Carlson \\
\hline AhR40 & Biotype R; pharyngitis; 17 year old male; 1992 & Petteri Carlson \\
\hline AhR41 & Biotype R; pharyngitis; 24 year old male; 1992 & Petteri Carlson \\
\hline AhR42 & Biotype R; pharyngitis; 16 year old female; 1992 & Petteri Carlson \\
\hline AhR43 & Biotype R; pharyngitis; 12 year old male; 1992 & Petteri Carlson \\
\hline AhR44 & Biotype R; pharyngitis; 18 year old male; 1992 & Petteri Carlson \\
\hline AhR45 & Biotype R; pharyngitis; 16 year old male; 1992 & Petteri Carlson \\
\hline
\end{tabular}


Table 1 Arcanobacterium strains used in this study. (Continued)

\begin{tabular}{lll}
\hline AhR46 & Biotype R; pharyngitis; 14 year old female; 1992 & Petteri Carlson \\
\hline AhR47 & Biotype R; pharyngitis; 13 year old female; 1991 & Petteri Carlson \\
\hline AhR48 & Biotype R; pharyngitis; 15 year old male; 1992 & Petteri Carlson \\
\hline AhR49 & Biotype R; pharyngitis; 20 year old male; 1991 & Petteri Carlson \\
\hline AhR50 & Biotype R; pharyngitis; 19 year old female; 1992 & Petteri Carlson \\
\hline CCUG39796 & Biotype unknown; infected leg ulcer; 52 year old male; 1998 & Petteri Carlson \\
\hline ATCC9345; DSM 20595 & Biotype unknown, 1946 & American Type Culture Collection; \\
\hline Trueperella (Arcanobacterium) pyogenes & $\begin{array}{l}\text { plo nanH nanP cbpA fimAB tet(W); Isolated from a bovine } \\
\text { BBR1 }\end{array}$ & {$[12]$} \\
\hline
\end{tabular}

* S, Smooth type; R, rough type.

CTATGAACGATGTTCTTG), cloned into expression vector pET28a (Novagen) using NheI and XhoI sites (underlined), and confirmed by sequencing. The plo gene encoding PLO was amplified from $T$. pyogenes ATCC 49698 DNA using the primers PYO28-F (GCCGCCCATATGGCCGGATTGGGAAACAGTTCG) and PYO-R (GCCGCCCTCGAGCTAGGATTTGACATTTTCCTC), cloned into pET28a using NdeI and XhoI sites (underlined), and confirmed by sequencing. The ily gene encoding ILY was amplified from Streptococcus intermedius and cloned into pET28a as described [22]. Purification of the His-tagged CDCs was as previously described [22,23].

\section{SDS-PAGE and Western blotting}

Proteins were separated by electrophoresis in $10 \%(\mathrm{w} / \mathrm{v})$ SDS-polyacrylamide gels and transferred to nitrocellulose [15]. Western blots were immunostained using rabbit anti-His-ALN (prepared by immunization of a rabbit with His-ALN, Antibodies Inc., Davis, CA) and rabbit anti-goat $\operatorname{IgG}(\mathrm{H}+\mathrm{L})$-peroxidase conjugate $(\mathrm{KPL})$, as the primary and secondary antibodies, respectively. Rabbit antiserum against PFO was kindly provided by Rodney K. Tweten, University of Oklahoma Health Sciences Center, OK.

\section{Hemolytic assays}

The hemolytic titers of His-ALN preparations were determined by incubation of two-fold serial dilutions of protein with an equal volume of $0.5 \%$ blood (Cleveland Scientific, Bath, $\mathrm{OH}$ ) at $37^{\circ} \mathrm{C}$ for $1 \mathrm{~h}$ [14]. The hemolytic titer was the reciprocal of the highest dilution which resulted in 50\% cell lysis, expressed as hemolytic units (HU) [14]. The specific activity of purified His-ALN was determined as $\mathrm{HU} / \mu \mathrm{g}$ protein. Thiol activation was assessed by incubation of $5 \mathrm{HU}$ His-ALN with $2 \% \beta$ mercaptoethanol for $10 \mathrm{~min}$ at room temperature, prior to performing a hemolytic assay with human blood (Cleveland Scientific). Cholesterol inhibition was assessed by incubation of $5 \mathrm{HU}$ His-ALN with $0.01-1 \mu \mathrm{M}$ cholesterol for $30 \mathrm{~min}$ at room temperature with shaking, prior to performing a hemolytic assay with human blood. Cholesterol was diluted in absolute ethanol and an equal volume of ethanol was used as the cholesterolfree control. His-tagged perfringolysin O (PFO) [24] and His-tagged PLO [14] were used as controls in the various hemolytic assays. For some experiments hemolysis assays were performed as described [22,23].

\section{Epithelial cell cytotoxicity}

The epithelial cell cytotoxicity of His-ALN was determined using the CellTiter $\left.96^{(}\right)$Aqueous One Solution Cell Proliferation Assay (Promega). A549 (human lung, CCL-185), CHO (hamster ovary, CCL-61), HCT-8 (human colon, CCL-244), J774A.1 (mouse macrophage, TIB-67), MDBK (bovine kidney, CCL-22), MDCK (canine kidney, CCL-34) and RK-13 (rabbit kidney, CCL-37) cells were cultured in Iscove's Modified Dulbecco's Medium or RMPI 1640 with $10 \%$ fetal bovine serum and $10 \mu \mathrm{g} / \mathrm{ml}$ gentamicin in a humidified, $5 \%$ $\mathrm{CO}_{2}$ atmosphere at $37^{\circ} \mathrm{C}$. Cells were seeded into 96-well plates at $2 \times 10^{4}$ cells/well and incubated for $18 \mathrm{~h}$ to achieve $80 \%$ confluence. Triplicate wells were incubated with doubling dilutions of His-ALN (0-2000 ng) and incubated for $2 \mathrm{~h}$, prior to addition of substrate for $3 \mathrm{~h}$. Determination of cell viability was performed using the appropriate control values (Promega).

\section{Membrane binding assay}

The membrane binding assay was performed using erythrocytes as previously described [25]. His-ALN was diluted to $12.5 \mu \mathrm{g} \mathrm{ml} \mathrm{g}^{-1}$ in PBS, $40 \mu \mathrm{l}$ was added to an equal volume of $50 \%(\mathrm{v} / \mathrm{v})$ blood and the mixture was incubated on ice for $20 \mathrm{~min}$. Cells were harvested by centrifugation at $14,000 \mathrm{~g}$ for $5 \mathrm{~min}$ at $4^{\circ} \mathrm{C}$, resuspended in SDS-PAGE sample buffer and subjected to SDSPAGE and Western blotting with antiserum against HisALN. 


\section{Results}

Cloning and nucleotide sequence determination of aln A draft genome sequence of $A$. haemolyticum ATCC 9345 was determined and consists of 46 contigs that encompass $\sim 1.945 \mathrm{Mb}$ in size (D. J. McGee, S. J. Billington, and B. J. Jost, unpublished). 1,639 ORFs were preliminarily identified using the Rapid Annotation using Subsystem Technology (RAST) Server [26]. Within this sequence, we identified ORF Arch_1062, the translation of which displayed similarity to other CDCs. The 1,710 bp gene was designated $a l n$, for arcanolysin (ALN). Upstream of $a l n$ are a phosphoglycerate mutase gene (pgm; Arch_1063) (EC 5.4.2.1) and an alanine tRNA GGC (Figure 1). In the 426 bp intergenic region are regulatory signals predicted to be involved in aln transcription, including a putative $\sigma^{70}$ promoter and 3 direct repeats (ATTTT $(G / C)(G / T) T)$ which are similar to those found immediately upstream of plo, encoding PLO, the CDC of $T$. pyogenes [27]. 6 bp downstream of $a l n$ is a transcriptional terminator with a $\Delta \mathrm{G}=-18.05 \mathrm{kcal} / \mathrm{mol}$. Downstream of $a l n$ and divergently transcribed is Arch_1061. The Arch_1061 protein displays amino acid similarity to hypothetical proteins from a number of genome sequences, including Corynebacterium jeikeium (GenBank YP_249820.1), and features a signal sequence. Further downstream is an additional alanine tRNA CGC, $_{\text {, }}$ which is $91 \%$ identical at the nucleotide level to the ala-

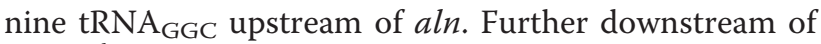
the $2^{\text {nd }}$ alanine tRNA is Arch_1060, a gene that is predicted to encode a conserved hypothetical protein related to Corynebacterium diphtheriae (DIP0761), and a gene, Arch_1059 (ubiE), with similarity to type II or SAM-dependent methyltransferases (EC 2.1.1.-).

The $\% \mathrm{G}+\mathrm{C}$ for aln is $46.7 \%$ (Figure 1 ) compared with 49.7-60.3\% for the surrounding genes and $53.1 \%$ for the entire genome. Given the lower $\% \mathrm{G}+\mathrm{C}$ of the aln gene and the presence of flanking tRNA genes, which can act as sites of foreign gene insertion [28], it is possible that

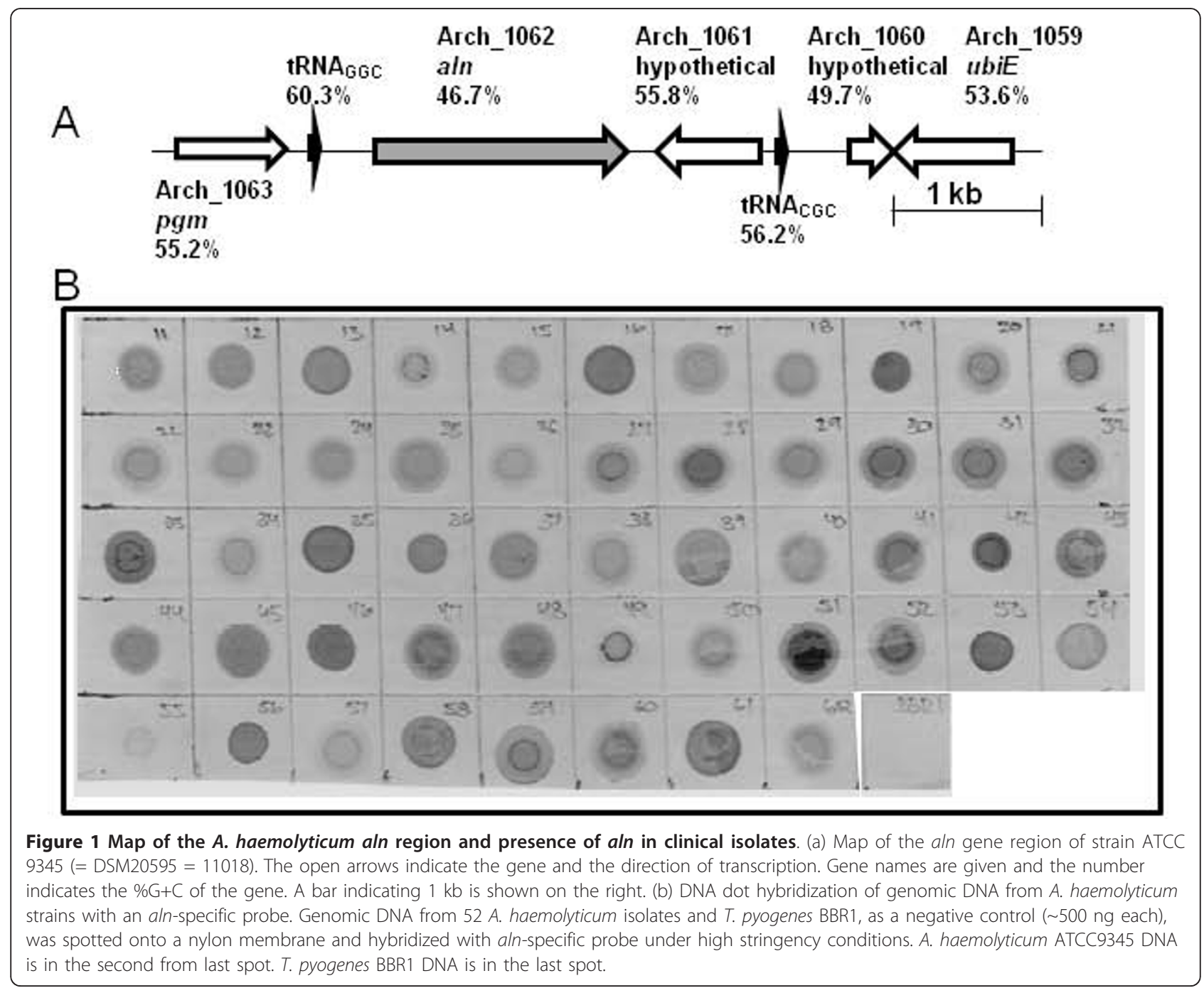


the A. haemolyticum aln gene was acquired by horizontal gene transfer.

\section{aln is widely distributed in A. haemolyticum isolates}

The prevalence of the aln gene was determined by DNA hybridization. A DIG-labeled probe spanning bases 492 1,052 of the aln ORF was hybridized to genomic DNA from A. haemolyticum ATCC9345, 51 A. haemolyticum clinical isolates (Table 1 ) and $T$. pyogenes BBR1, as a negative control. The aln probe hybridized at high stringency to all $A$. haemolyticum isolates $(\mathrm{n}=52)$, but not $T$. pyogenes genomic DNA (Figure $1 \mathrm{~b}$ ), indicating that this gene appears to be highly prevalent in A. haemolyticum. The region of aln from which the probe was derived has $62.8 \%$ identity to the corresponding nucleotide region in plo of $T$. pyogenes. Under high stringency hybridization conditions, DNA sequences which are less than $70 \%$ identical do not hybridize.

\section{Analysis of the primary structure of ALN}

The predicted ALN protein is 569 amino acids in length, including a 26 amino acid signal sequence predicted by SignalP. The mature protein lacking the signal sequence has a predicted molecular mass of $60.1 \mathrm{kDa}$. ALN is most similar to PLO with $59.4 \%$ and $71.5 \%$ amino acid identity and similarity (Figure 2) and has $\sim 50 \%$ similarity to other CDC family members. Within

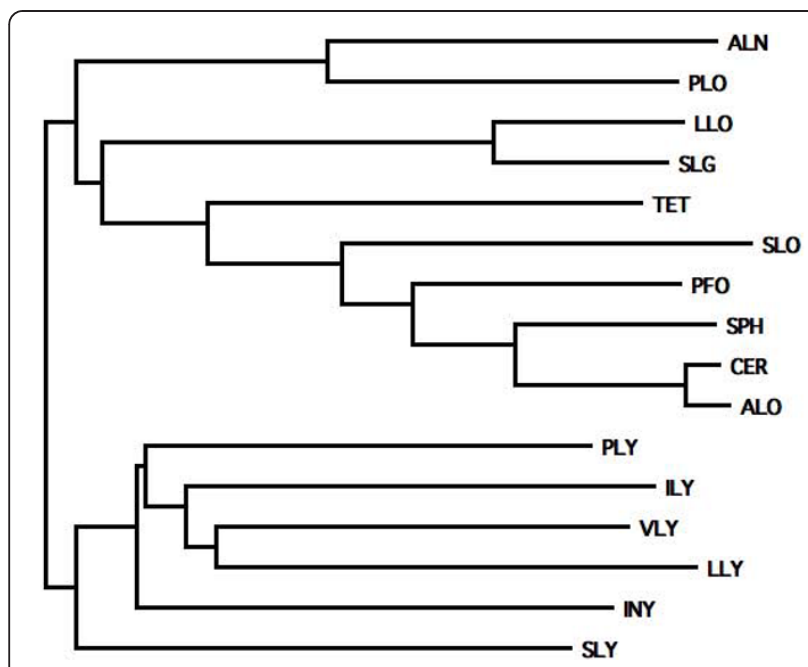

Figure 2 Neighbor joining tree of amino acid sequences showing the relationship of ALN to other selected CDC family members. Abbreviations and gi ascession numbers from the NCBI protein database: ALN, arcanolysin (259156857); PLO, pyolysin (2252800); LLO, listeriolysin O (16802248); SLG seeligeriolysin (40889013); TET, tetanolysin (28211522); SLO, streptolysin O (15674372); PFO, perfringolysin O (18309145); SPH, sphaericolysin (146455206); CER, cereolysin (62550724); ALO, anthrolysin O (49186114); PLY, pneumolysin (15901747); ILY, intermedilysin (6729344); VLY, vaginolysin (187940699); LLY, lectinolysin (190576835); INY, inerolysin (259167149); SLY, suilysin (253752120). the ALN N-terminus, the pestfind algorithm identified a putative PEST sequence not present in PLO or most other CDC sequences (Figure 3a). Listeriolysin O (LLO), which contains a bona fide PEST sequence [29], returned a pestfind score of 4.71, while ALN had a score of 7.58, indicating a higher probability of containing a functional PEST sequence. Given that A. haemolyticum invades host cells [9], it is possible that the PEST sequence allows for a similar compartmentalization of ALN activity within the host cell. Like PLO, the predicted amino acid sequence of ALN has a variant undecapeptide in domain 4 and both lack the conserved cysteine residue (Figure $3 \mathrm{~b}$ ). The tryptophan spacing of ALN and PLO (WxxWW) also differs from the consensus sequence (WxWW) (Figure 3b).

\section{Cloning and expression of His-ALN}

SDS-PAGE and Coomassie Brilliant Blue staining of IPTG-induced cultures of pBJ51-containing $E$. coli indicated the presence of an over-expressed protein of $\sim 64$ $\mathrm{kDa}$ (Figure 4a). His-ALN was purified to > 95\% homogeneity using TALON resin (Figure 4a), and the size of this protein $(\sim 64 \mathrm{kDa})$ corresponded to its predicted molecular mass. Antiserum against ALN, but not preimmune antiserum, reacted specifically with His-ALN and some possible HIS-ALN degradation products (Figure $4 \mathrm{~b}$ and $4 \mathrm{c}$ ).

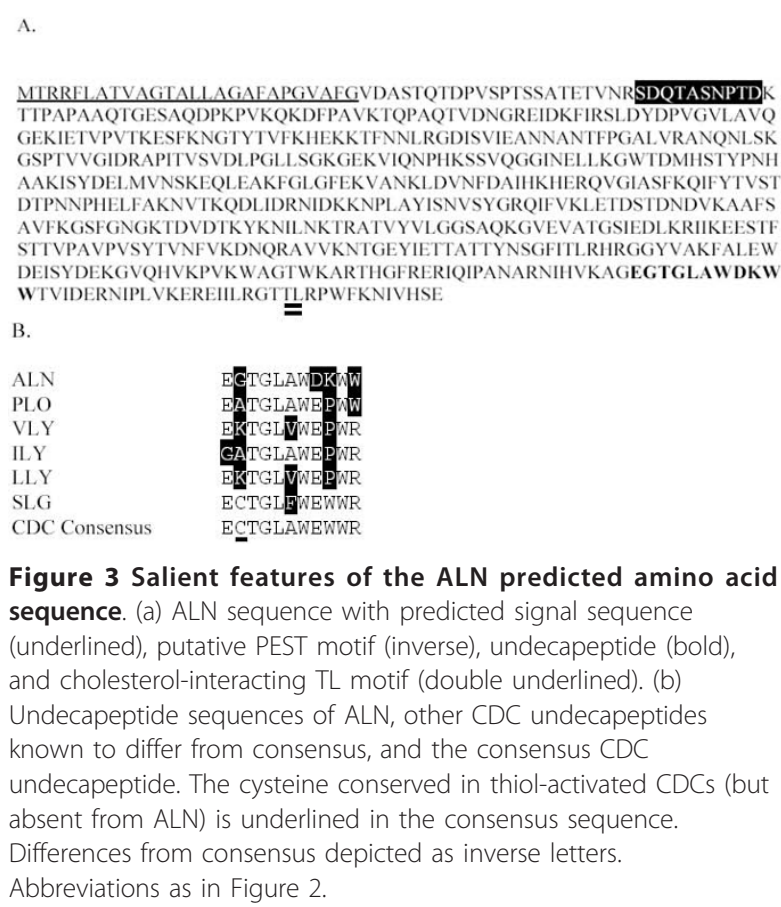
AAKISYDELMVNSKEQLEAKFGLGFEKVANKLDVNFDAIHKHERQVGIASFKQIFYTVST
DTPNNPHELFAKNVTKQDLIDRNIDKKNPLAYISNVSYGRQIFVKLETDSTDNDVKAAFS DTPNNPHELFAKNVTKQDLIDRNIDKKNPLAYISNVSYGRQIFVKLETDSTDNDVKAAFS AVFKGSFGNGKTDVDTKYKNILNKTRATVYVLGGSAQKGVEVATGSIEDLKRIIKEESTI STTVPAVPVSYTVNFVKDNQRAVVKNTGEYIETTATTYNSGFITLRHRGGYVAKFALEW B.

Figure 3 Salient features of the ALN predicted amino acid sequence. (a) ALN sequence with predicted signal sequence (underlined), putative PEST motif (inverse), undecapeptide (bold), and cholesterol-interacting TL motif (double underlined). (b) Undecapeptide sequences of ALN, other CDC undecapeptides known to differ from consensus, and the consensus CDC undecapeptide. The cysteine conserved in thiol-activated CDCs (but absent from ALN) is underlined in the consensus sequence. Differences from consensus depicted as inverse letters. Abbreviations as in Figure 2. 


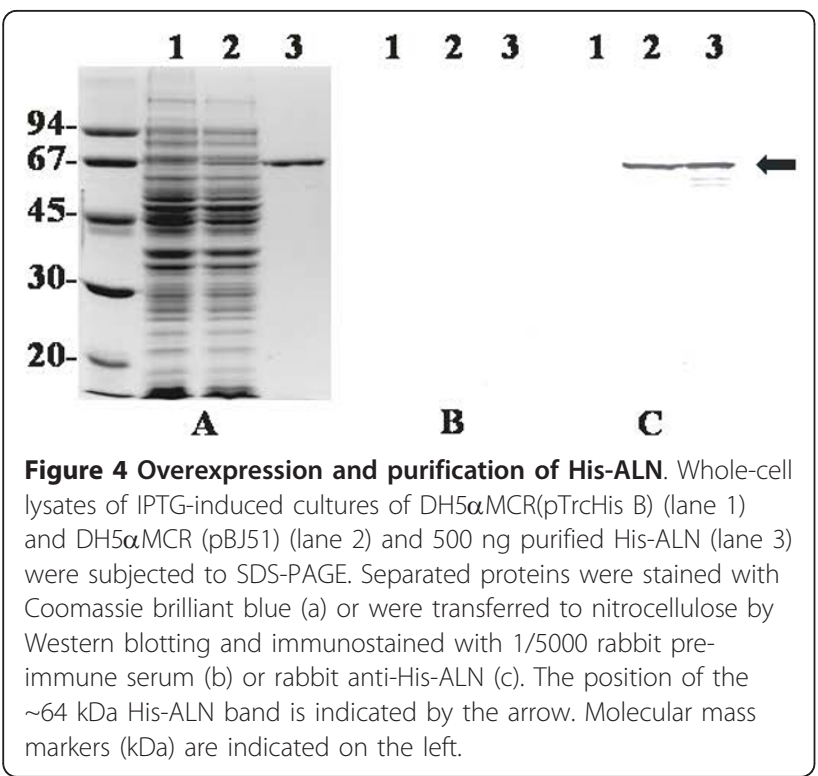

\section{Recombinant ALN has cytotoxic activity}

A. haemolyticum is not strongly hemolytic when grown on ovine (sheep) blood agar [10]. Likewise, the E. coli strain expressing His-ALN did not display hemolysis when grown on bovine blood agar (data not shown). Similarly, His-ALN displays low hemolysis with bovine or ovine erythrocytes (Figure $5 \mathrm{a}$ ). In contrast, His-ALN had $~ 4$ - and 10-fold increased hemolytic activity on rabbit and human erythrocytes, respectively (Figure 5a). This is in contrast to PFO or PLO, which show little difference in specific activity on erythrocytes from different hosts. Consistent with these findings, hemolysis assays demonstrated that ALN has a preference for horse or human cells over porcine cells but lyses all of these at high toxin concentrations (Figure 5b). This is in contrast to intermedilysin (ILY) from Streptococcus intermedius, which retains human-specific tropism over a wide concentration range, and PLO, which is less selective than ALN (Figure 5b).

The highly-conserved Cys residue in the undecapeptide of CDCs is responsible for Thiol activation of this group of toxins [30]. ALN lacks the Cys residue in the undecapeptide (Figure 3a), and like PLO [14], its activity was unaffected by treatment with $\beta$-mercaptoethanol (data not shown).

We also determined the effect of recombinant ALN on cultured mammalian cells. His-ALN was applied to human, bovine, canine, hamster, mouse and rabbit cell lines and was highly active on human and rabbit cells (Figure 5c), with low activity on bovine, mouse and canine cells. This toxin had intermediate activity on hamster cells (Figure 5c). This finding mirrors the activity of ALN on blood from different host species (Figure $5 \mathrm{a}$ ), and is less species-specific than intermedilysin (ILY) or vaginolysin (VLY) [23,31]. ILY, VLY, and lectinolysin (LLY) use human CD59 (hCD59) as a membrane receptor $[23,32,33]$, leading to host-specificity. Unlike these other CDC toxins ALN hemolysis was not blocked with a monoclonal antibody against hCD59 (data not shown). Consistent with this finding, the predicted ALN amino acid sequence lacks the Tyr-X-Tyr- $\mathrm{X}_{14}$-Ser-Arg signature motif common to all known hCD59-dependent CDCs [33].

\section{The activity of ALN is less sensitive to cholesterol inhibition than PFO}

Given the more restrictive host species preference of ALN over that of PFO, along with the variant undecapeptide sequence in ALN, we hypothesized that ALN might be less sensitive to inhibition by free cholesterol. As expected, PFO activity was almost completely inhibited by exogenous $0.5 \mu \mathrm{M}$ cholesterol (7.6\%; Figure 6). In contrast, PLO and ALN retained $52.5 \%$ and $41.4 \%$ activity, respectively, when incubated with $0.5 \mu \mathrm{M}$ cholesterol and retained $\sim 20 \%$ of hemolytic activity at $1 \mu \mathrm{M}$ cholesterol (Figure 6). These data indicate that ALN and PLO have intermediate sensitivity to cholesterol compared to a CDC (PFO) with the conserved undecapeptide sequence.

\section{ALN binds differentially to host cell membranes}

Hemolytic assays measure the full spectrum of CDC binding, oligomerization and pore formation leading to cell lysis. However, initial toxin binding to membranes can be determined by incubation of CDCs with host cells at $4^{\circ} \mathrm{C}$, which prevents subsequent oligomerization and pore formation [34]. Using this approach, His-ALN bound to human and rabbit erythrocytes as determined by Western blotting (Figure 7). Probable ALN degradation products were also detected. His-ALN did not exhibit detectable binding to bovine or ovine erythrocyte membranes under these conditions. As a control, HisPFO was incubated with human, bovine, ovine or rabbit erythrocytes, and bound toxin was detected with antiPFO antiserum. His-PFO bound to all cell types at approximately equivalent amounts (data not shown). These data suggest that ALN host preference may occur at the initial contact of the toxin with the host cell membrane.

\section{Discussion}

The CDCs are a family of bacterial toxins produced by diverse Gram-positive bacteria and are generally important in pathogenesis [35-37]. CDCs have a four-domain structure and a conserved C-terminal undecapeptide sequence in domain 4 that is important for toxin function. Soluble CDC monomers bind to host membrane targets, oligomerize into a large homomeric structure 


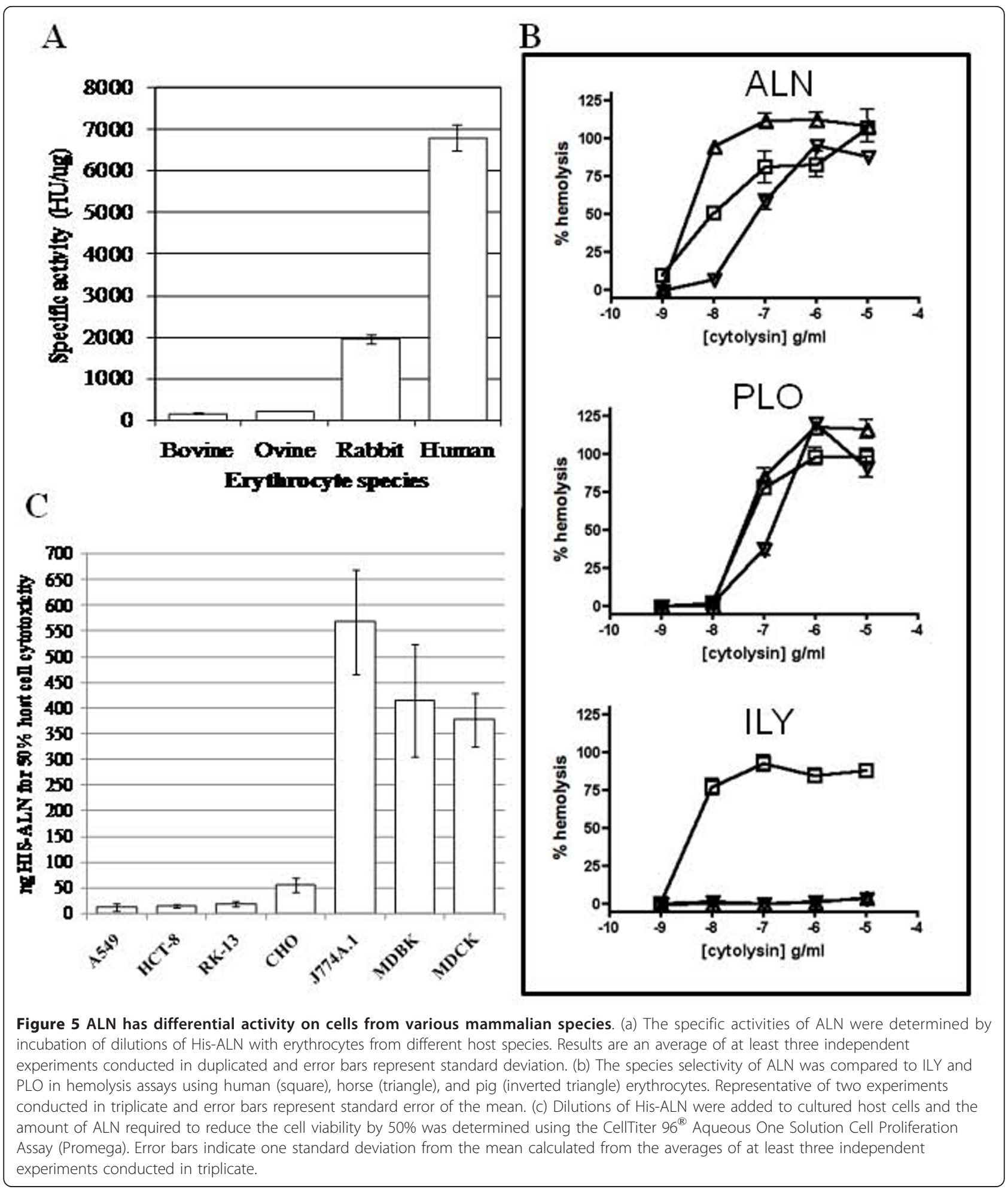

known as the prepore complex, and transition to a true pore, leading to cytolysis of target cells [38]. CDCs interact with membrane cholesterol through a conserved threonine-leucine pair in domain 4 , and this interaction is crucial to the formation of functional pores [39].
Some CDCs, including ILY, VLY, and LLY, require the presence of hCD59 as a membrane receptor, conferring human-specific activity $[23,33,40]$. Among the CDCs, PLO is unusual, as it contains a variant of the highly conserved domain 4 undecapeptide, and this divergent 


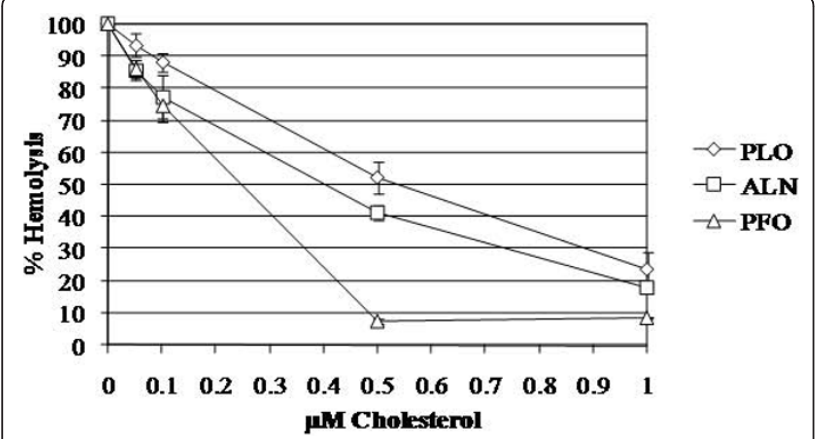

Figure 6 ALN, a cholesterol-dependent cytolysin, has hemolytic activity that is less sensitive to cholesterol inhibition than PFO. His-tagged CDCs were preincubated with dilutions of cholesterol for $30 \mathrm{~min}$ at room temperature prior to hemolytic assay. Abbreviations as in Figure 2. Error bars indicate one standard deviation from the mean calculated from the averages of three independent experiments conducted in triplicate.

sequence is essential for full PLO activity [41]. The ALN undecapeptide is most similar to that of PLO (Figure $3 \mathrm{~B})$, in that it retains the three tryptophan residues of the consensus undecapeptide but employs an alternate spacing (i.e. WxxWW rather than WxWW). The tryptophan residues of the undecapeptide are known to be important for insertion of domain 4 into host cell membranes [42]. Like the human-specific CDCs (VLY, ILY, and LLY), ALN contains a proline in its undecapeptide sequence. However, the hemolytic activity of ALN was

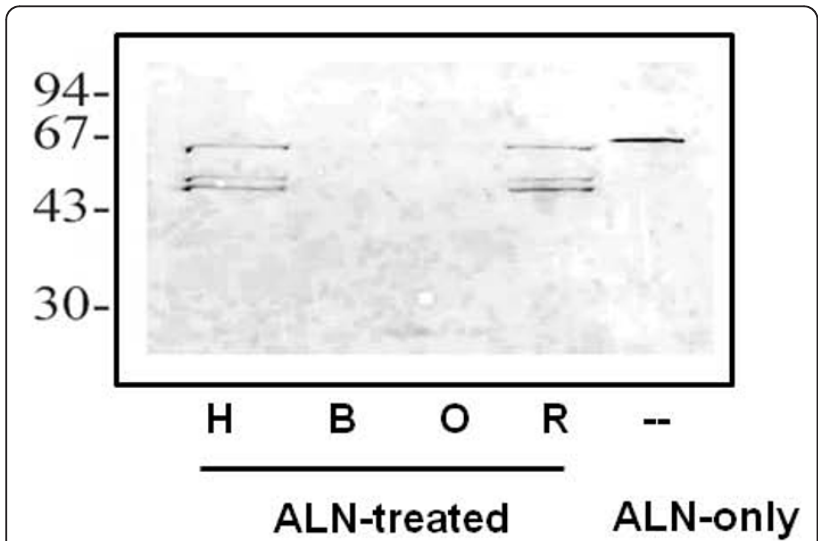

Figure $7 \mathrm{ALN}$ has a differential ability to bind to erythrocyte cell membranes from different host species. His-ALN (500 ng) or buffer (negative control) was added to erythrocytes, and the mixture was incubated on ice for 20 min. Untreated (no reactivity, data not shown) or ALN-treated erythrocyte membrane fractions from human $(\mathrm{H})$, bovine $(\mathrm{B})$, ovine $(\mathrm{O})$ or rabbit $(\mathrm{R})$ blood were separated by SDS-PAGE, transferred to nitrocellulose, and immunostained with 1/1000 rabbit anti-His-ALN. His-Aln (500 ng) in absence of erythrocyte membrane fractions (ALN) serves as the positive control. Molecular mass markers $(\mathrm{kDa})$ are indicated on the left. not blocked by antibodies to human CD59, which acts as a receptor for the human-specific CDCs [23,32,33], suggesting that ALN may interact with a distinct membrane receptor, perhaps in addition to cholesterol. The nature of the ALN receptor is currently unknown and is under investigation. Although the cysteine residue in the consensus undecapeptide confers the property of thiol activation to CDCs, the cysteine is not essential for streptolysin $\mathrm{O}$ and pneumolysin toxin function $[43,44]$. The human-specific CDCs (VLY, ILY, LLY), PLO, and ALN all lack this conserved cysteine residue, but the contribution of this sequence variation to toxin function is not yet known for these toxins.

Some CDCs have a number of functions beyond simple pore formation. Streptococcus pyogenes uses streptolysin $\mathrm{O}$ to introduce a bacterial effector into host cells via a novel mechanism termed cytolysin-mediated translocation (CMT) [45]. At sublytic concentrations, CDCs may act as ligands for toll-like receptors $[46,47]$ and may induce a cycle of p38 mitogen-activated protein kinase (MAPK) phosphorylation and dephosphorylation $[48,49]$. LLO allows Listeria monocytogenes to escape from the vacuole into the cytoplasm where the organism can rapidly multiply [50]. The site-specific nature of LLO is controlled by cytosolic down-regulation of LLO function due to an N-terminal PEST-like sequence, which usually targets eukaryotic proteins for cytosolic degradation. The PEST sequence results in a substantially reduced half-life of LLO in the cytoplasm of the host cell [29].

\section{Conclusions}

ALN has several unique features among the CDC family. ALN has a variant undecapeptide and possesses an unusual $\mathrm{N}$-terminal extension, with a putative PEST sequence. Moreover, ALN lacks the conserved cysteine of thiol-activated CDCs, explaining why $\beta$-mercaptothanol had no effect on ALN function. The unique sequences and predicted structural features of ALN will make it an interesting toxin to conduct future structurefunction analyses to identify additional unique properties of this toxin. ALN displays an unusual pattern of target cell species selectivity, with high activity against human, horse, and rabbit cells and lesser activity against cells derived from other species. This selectivity appears to function at the level of membrane binding and may contribute to the host range of A. haemolyticum. Further work will focus on understanding the role of ALN in A. haemolyticum pathogenesis.

\section{Acknowledgements}

The authors thank Petteri Carlson, University of Helsinki for providing the A. haemolyticum isolates, and Maricela V. Pier and Andrew E. Clark, University of Arizona for technical assistance. Support for this work was provided by 
USDA Hatch ARZT-136828-H-02-129, the College of Agriculture and Life Sciences, University of Arizona to BHJ, National Institutes of Health R01Al092743 to AJR, and start-up funds from LSU Health Sciences CenterShreveport to DJM.

\section{Author details}

${ }^{1}$ Department of Veterinary Science and Microbiology, The University of Arizona, 1117 E Lowell Street, Tucson, AZ 85721, USA. ² Ventana Medical Systems, Inc., 1910 Innovation Park Drive, Oro Valley, AZ 85755, USA. ${ }^{3}$ Columbia University, Department of Pediatrics and Microbiology \& Immunology, $650 \mathrm{~W} 168^{\text {th }}$ Street BB443, New York, NY 10032, USA. ${ }^{4}$ Louisiana State University Health Sciences Center-Shreveport, Department of Microbiology \& Immunology, 1501 Kings Highway, Shreveport, LA 71130, USA.

\section{Authors' contributions}

$B H J, E A L$ and AJR designed and conducted the experiments and analyzed data, BHJ drafted the manuscript, AJR, SJB and DJM revised the manuscript and figures. All authors read and approved the final manuscript.

\section{Competing interests}

The authors declare that they have no competing interests.

Received: 30 June 2011 Accepted: 26 October 2011

Published: 26 October 2011

\section{References}

1. Linder R: Rhodococcus equi and Arcanobacterium haemolyticum: two "coryneform" bacteria increasingly recognized as agents of human infection. Emerging Infectious Diseases 1997, 3:145-153.

2. Banck G, Nyman M: Tonsillitis and rash associated with Corynebacterium haemolyticum. J Infect Dis 1986, 154:1037-1040.

3. Mackenzie A, Fuite LA, Chan FT, King J, Allen U, MacDonald N, DiazMitoma F: Incidence and pathogenicity of Arcanobacterium haemolyticum during a 2-year study in Ottawa. Clin Infect Dis 1995, 21:177-181.

4. Miller RA, Brancato F, Holmes KK: Corynebacterium haemolyticum as a cause of pharyngitis and scarlatiniform rash in young adults. Ann Intern Med 1986, 105:867-872.

5. Collins MD, Jones D, Schofield GM: Reclassification of 'Corynebacterium haemolyticum' (MacLean, Liebow \& Rosenberg) in the genus Arcanobacterium gen. nov. as Arcanobacterium haemolyticum nom. rev. comb. nov. J Gen Microbiol 1982, 128:1279-1281.

6. Jost BH, Billington SJ: Arcanobacterium pyogenes: molecular pathogenesis of an animal opportunist. Antonie van Leeuwenhoek 2005, 88:87-102.

7. Cuevas WA, Songer JG: Arcanobacterium haemolyticum phospholipase D is genetically and functionally similar to Corynebacterium pseudotuberculosis phospholipase D. Infect Immun 1993, 61:4310-4316.

8. Soucek A, Souckova A: Toxicity of bacterial sphingomyelinases D. J Hyg Epidemiol Microbiol Immunol 1974, 18:327-335.

9. Lucas EA, Billington SJ, Carlson P, McGee DJ, Jost BH: Phospholipase D promotes Arcanobacterium haemolyticum adhesion via lipid raft remodeling and host cell death following bacterial invasion. BMC Microbiology 2010, 10:270.

10. Funke G, von Graevenitz A, Clarridge III JE, Bernard KA: Clinical microbiology of coryneform bacteria. Clin Microbiol Rev 1997, 10:125-159.

11. Hassan AA, Ulbegi-Mohyla H, Kanbar T, Alber J, Lammler C, Abdulmawjood A, Zschock M, Weiss R: Phenotypic and genotypic characterization of Arcanobacterium haemolyticum isolates from infections of horses. Journal of Clinical Microbiology 2009, 47(1):124-128

12. MacLean PD, Liebow AA, Rosenberg AA: A haemolytic bacterium resembling Corynebacterium ovis and Corynebacterium pyogenes in man. J Infect Dis 1946, 79:69-90.

13. Linder R, Bernheimer AW: Enzymatic oxidation of membrane cholesterol in relation to lysis of sheep erythrocytes by corynebacterial enzymes. Arch Biochem Biophys 1982, 213:395-404.

14. Billington SJ, Jost BH, Cuevas WA, Bright KR, Songer JG: The Arcanobacterium (Actinomyces) pyogenes hemolysin, pyolysin, is a novel member of the thiol-activated cytolysin family. J Bacteriol 1997, 179:6100-6106.
15. Ausubel FM, Brent R, Kingston RE, Moore DD, Seidman JG, Smith JA, Struhl K: Current protocols in molecular biology. New York, NY: Greene Publishing Associates and John Wiley and Sons, Inc.; 19941.

16. Yasawong M, Teshima H, Lapidus A, Nolan M, Lucas S, Glavina Del Rio T, Tice H, Cheng JF, Bruce D, Detter C, et al: Complete genome sequence of Arcanobacterium haemolyticum type strain (11018). Stand Genomic Sci 2010, 3(2):126-135.

17. Altschul SF, Madden TL, Schäffer AA, Zhang J, Zhang Z, Miller W, Lipman DJ: Gapped BLAST and PSI-BLAST: a new generation of protein database search programs. Nucleic Acids Res 1997, 25:3389-3402.

18. Lowe TM, Eddy SR: tRNAscan-SE: a program for improved detection of transfer RNA genes in genomic sequence. Nucl Acids Res 1997, 25:955-964.

19. Nielsen H, Engelbrecht J, Brunak S, von Heijne G: Identification of prokaryotic and eukaryotic signal peptides and prediction of their cleavage sites. Protein Eng 1997, 10:1-6.

20. Zucker M: Mfold web server for nucleic acid folding and hybridization prediction. Nucl Acids Res 2003, 31:3406-3415.

21. Thompson JD, Higgins DG, Gibson TJ: CLUSTAL W: improving the sensitivity of progressive multiple sequence alignment through sequence weighting, position-specific gap penalties and weight matrix choice. Nucleic Acids Res 1994, 22:4673-4680.

22. Rampersaud R, Planet PJ, Randis TM, Kulkarni R, Aguilar JL, Lehrer RI, Ratner AJ: Inerolysin, a cholesterol-dependent cytolysin produced by Lactobacillus iners. Journal of Bacteriology 2011, 193(5):1034-1041.

23. Gelber SE, Aguilar JL, Lewis KL, Ratner AJ: Functional and phylogenetic characterization of Vaginolysin, the human-specific cytolysin from Gardnerella vaginalis. Journal of Bacteriology 2008, 190(11):3896-3903.

24. Fernandez-Miyakawa ME, Jost BH, Billington SJ, Uzal FA: Lethal effects of Clostridium perfringens epsilon toxin are potentiated by alpha and perfringolysin-O toxins in a mouse model. Vet Microbiol 2007, 127:379-385.

25. Jost BH, Trinh HT, Songer JG, Billington SJ: Immunization with genetic toxoids of the Arcanobacterium pyogenes cholesterol-dependent cytolysin, pyolysin, protects mice against infection. Infect Immun 2003, 71:2966-2969.

26. Meyer F, Paarmann D, D'Souza M, Olson RD, Glass EM, Kubal M, Paczian T, Rodriguez A, Stevens R, Wilke A, et al: The metagenomics RAST server - a public resource for the automatic phylogenetic and functional analysis of metagenomes. BMC Bioinformatics 2008, 9:386.

27. Rudnick ST, Jost BH, Songer JG, Billington SJ: The gene encoding pyolysin, the pore-forming toxin of Arcanobacterium pyogenes, resides within a genomic islet flanked by essential genes. FEMS Microbiol Lett 2003, 225:241-247.

28. Williams KP: Integration sites for genetic elements in prokaryotic tRNA and tmRNA genes: sublocation preference of integrase subfamilies. Nucl Acids Res 2002, 30:866-875.

29. Decatur AL, Portnoy DA: A PEST-like sequence in listeriolysin O essential for Listeria monocytogenes pathogenicity. Science 2000, 290:992-995.

30. Alouf JE, Billington SJ, Jost BH: Repertoire and general features of the family of cholesterol-dependent cytolysins. In The comprehensive sourcebook of bacterial protein toxins. 3 edition. Edited by: Alouf JE, Popoff MR. London: Academic Press; 2006:643-658.

31. Nagamune H: Streptococcal cytolysins. Seikagaku 1997, 69:343-348,

32. Giddings KS, Zhao J, Sims PJ, Tweten RK: Human CD59 is a receptor for the cholesterol-dependent cytolysin intermedilysin. Nat Struct Mol Biol 2004, 11:1173-1178.

33. Wickham SE, Hotze EM, Farrand AJ, Polekhina G, Nero TL, Tomlinson S, Parker MW, Tweten RK: Mapping the Intermedilysin-Human CD59 Receptor Interface Reveals a Deep Correspondence with the Binding Site on CD59 for Complement Binding Proteins C8\{alpha\} and C9. J Biol Chem 2011, 286(23):20952-20962.

34. de los Toyos JR, Mendez FJ, Aparicio JF, Vázquez F, del Mar García Suárez M, Fleites A, Hardisson C, Morgan PJ, Andrew PW, Mitchell TJ: Functional analysis of pneumolysin by use of monoclonal antibodies. Infect Immun 1996, 64:480-484.

35. Gilbert RJ: Cholesterol-dependent cytolysins. Advances in Experimental Medicine \& Biology 2010, 677:56-66.

36. Heuck AP, Moe PC, Johnson BB: The cholesterol-dependent cytolysin family of gram-positive bacterial toxins. Sub-Cellular Biochemistry 2010, 51:551-577. 
37. Tweten R: Cholesterol-dependent cytolysins, a family of versatile poreforming toxins. Infect Immun 2005, 73:6199-6209.

38. Heuck AP, Tweten RK, Johnson AE: Assembly and topography of the prepore complex in cholesterol-dependent cytolysins. J Biol Chem 2003, 278:31218-31225.

39. Farrand AJ, LaChapelle S, Hotze EM, Johnson AE, Tweten RK: Only two amino acids are essential for cytolytic toxin recognition of cholesterol at the membrane surface. Proceedings of the National Academy of Sciences of the United States of America 2010, 107(9):4341-4346.

40. Giddings KS, Johnson AE, Tweten RK: Redefining cholesterol's role in the mechanism of the cholesterol-dependent cytolysins. Proc Natl Acad Sci USA 2003, 100:11315-11320.

41. Billington SJ, Songer JG, Jost BH: The variant undecapeptide sequence of the Arcanobacterium pyogenes haemolysin, pyolysin, is required for full cytolytic activity. Microbiology 2002, 148:3947-3954.

42. Soltani CE, Hotze EM, Johnson AE, Tweten RK: Specific protein-membrane contacts are required for prepore and pore assembly by a cholesteroldependent cytolysin. Journal of Biological Chemistry 2007, 282(21):15709-15716.

43. Pinkney $M$, Beachey $E$, Kehoe $M$ : The thiol-activated toxin streptolysin $\mathrm{O}$ does not require a thiol group for cytolytic activity. Infect Immun 1989, 57:2553-2558.

44. Saunders FK, Mitchell TJ, Walker JA, Andrew PW, Boulnois GJ: Pneumolysin, the thiol-activated toxin of Streptococcus pneumoniae, does not require a thiol group for in vitro activity. Infect Immun 1989, 57:2547-2552.

45. Madden JC, Ruiz N, Caparon M: Cytolysin-mediated translocation (CMT): a functional equivalent of type III secretion in Gram-positive bacteria. Cell 2001, 104:143-152.

46. Malley R, Henneke P, Morse SC, Cieslewicz MJ, Lipsitch M, Thompson CM, Kurt-Jones E, Paton JC, Wessels MR, Golenbock DT: Recognition of pneumolysin by Toll-like receptor 4 confers resistance to pneumococcal infection. Proceedings of the National Academy of Sciences of the United States of America 2003, 100(4):1966-1971.

47. Park JM, Ng VH, Maeda S, Rest RF, Karin M: Anthrolysin O and other grampositive cytolysins are toll-like receptor 4 agonists. J Exp Med 2004, 200:1647-1655

48. Aguilar JL, Kulkarni R, Randis TM, Soman S, Kikuchi A, Yin Y, Ratner AJ: Phosphatase-dependent regulation of epithelial mitogen-activated protein kinase responses to toxin-induced membrane pores. PLOS ONE [Electronic Resource] 2009, 4(11):e8076.

49. Ratner AJ, Hippe KR, Aguilar JL, Bender MH, Nelson AL, Weiser JN: Epithelial cells are sensitive detectors of bacterial pore-forming toxins. Journal of Biological Chemistry 2006, 281(18):12994-12998.

50. Vazquez-Boland JA, Kuhn M, Berche P, Chakraborty T, Dominguez-Bernal G, Goebel W, Gonzalez-Zorn B, Wehland J, Kreft J: Listeria pathogenesis and molecular virulence determinants. Clin Microbiol Rev 2001, 14:584-640.

doi:10.1186/1471-2180-11-239

Cite this article as: Jost et al:: Arcanolysin is a cholesterol-dependent cytolysin of the human pathogen Arcanobacterium haemolyticum. BMC Microbiology 2011 11:239.

\section{Submit your next manuscript to BioMed Central and take full advantage of:}

- Convenient online submission

- Thorough peer review

- No space constraints or color figure charges

- Immediate publication on acceptance

- Inclusion in PubMed, CAS, Scopus and Google Scholar

- Research which is freely available for redistribution 